\title{
El arte de la traducción de Jiří Levý: desde la génesis del original hasta su recepción en el mundo hispanófono y lusófono ${ }^{1}$
}

\section{Jiří Levý's The Art of Translation: from the Genesis of the Original to its Reception in the Spanish and Portuguese- speaking World}

\author{
JELIZAVETA GETTA \\ getta1994@seznam.cz \\ Universidad Carolina de Praga
}

Fecha de recepción: 23 de octubre de 2020

Fecha de aceptación: 20 de enero de 2021

Resumen: En este artículo tratamos de describir la génesis de la obra fundamental de Jiři Levý El arte de la traducción (1963) desde los primeros años de la década de los cincuenta, así como los avatares de su accidentada recepción internacional hasta la actualidad. La primera edición checa de la obra fue precedida por toda una serie investigaciones interdisciplinarias de las que queda constancia en artículos, manuales, conferencias y notas manuscritas. Este proceso se prolongó en las traducciones al alemán y al ruso de la obra (1969 y 1974), en las cuales Levý colaboró estrechamente con sus traductores realizando adaptaciones y modificaciones de diversos tipos para acercar la obra a sus receptores en las culturas de destino. En particular, la traducción alemana fue importante porque sirvió para difundir las ideas de Levý en el extranjero y también porque fungió, junto con el original checo, como patrón en la segunda edición checa de la obra, preparada por Karel Hausenblas en 1983, y que ha servido de modelo para todas las ediciones posteriores. Durante mucho tiempo la obra de Levý permaneció desconocida para el público internacional por motivos de índole lingüística y política, entre otros. Sin embargo, en la última década hemos presenciado un renacimiento del interés por su concepción teórica, evidenciado en la aparición de nuevas traducciones, a la que se considera como precursora de inquietudes teóricas contemporáneas.

\footnotetext{
1 Este texto fue redactado gracias al apoyo financiero del proyecto GA UK n. 68420 « Překladatelská evoluce Umění překladu: Komparativní analýza českého originálu a jeho německého překladu, doplněná o komentáře překladatele ke spolupráci s autorem, Jiřím Levým», de la Facultad de Letras de la Universidad Carolina de Praga. El artículo es una adaptación con ciertas modificaciones del que se publicará próximamente, en checo, en la revista Svět literatury. La autora quiere agradecer a Michaela Pokorná y Cristian Cámara Outes su ayuda en la revisión del texto.
} 
Palabras clave: Jiři Levý, El arte de la traducción, Estructuralismo checo, Traductología, Historia de la traducción

Abstract: In this paper, we try to describe the genesis of Jiři Levý's groundbreaking work The Art of Translation (1963) from the early 1950s, as well as the vicissitudes of its international reception until the present day. The first Czech edition of the work was preceded by a whole series of interdisciplinary investigations recorded in articles, manuals, lectures and handwritten notes. This process was prolonged in the German and Russian translations of the work (1969 and 1974), in which Levý collaborated closely with his translators making adaptations and modifications of various kinds to bring the work closer to its recipients in the target cultures. In particular, the German translation was important because it served to spread Levý's ideas abroad and also because it acted, together with the Czech original, as a pattern in the second Czech edition of the work, prepared by Karel Hausenblas in 1983, which all subsequent editions have taken as model. For a long time, Levý's work remained unknown to international audiences for linguistic and political reasons, among others. However, in the last decade we have witnessed a revival of interest in his theoretical conception -evidenced in the appearance of new translations - which is considered now as a precursor of contemporary theoretical vistas.

Key words: Jiři Levý, The Art of Translation, Czech Structuralism, Translation Studies, History of Translation.

\section{INTRODUCCIÓN}

El arte de la traducción (Umění překladu), la obra más relevante del teórico de la traducción checo más destacado, Jiří Levý, resulta interesante no solo por sus contenidos doctrinales estrictos sino también por aspectos ecdóticos relacionados con sus procesos de escritura y recepción. El original checo de la obra fue publicado en 1963 y enseguida despertó interés en el extranjero. En 1969 apareció su primera traducción a una lengua extranjera, en concreto al alemán, y simultáneamente se realizaba la traducción al ruso. Dado que la terminología y argumentación desarrollada por Levý en el original estaban firmemente arraigadas en el contexto literario checo, la preparación de ambas versiones requirió importantes reelaboraciones lingüísticas y pragmáticas. El propio Levý se implicó activamente en este proceso de adaptación, cambiando los ejemplos originales checos por otros alemanes o rusos, y también aprovechó la oportunidad para actualizar la obra y añadir nuevas reflexiones. De esta manera, la versión alemana de la obra facilitó la difusión de las ideas de Levý en el extranjero y sirvió posteriormente como 
patrón, junto con el original, en la preparación de la segunda edición checa de El arte de la traducción, editada por Karel Hausenblas en 1983. En particular, esta traducción alemana fue la que más influyó en la recepción de la obra en España y América Latina.

Aunque ya han transcurrido casi 60 años desde la publicación de la primera edición, las ideas teóricas y conceptos elaborados por Levý en este trabajo siguen teniendo un extraordinario interés para las discusiones actuales. Durante las últimas décadas la obra se ha traducido a diversas lenguas y ahora vuelve a ser leída y redescubierta. En este artículo nos proponemos investigar la génesis de El arte de la traducción, sobre todo de su primera parte, y describir las etapas de su recepción en el contexto nacional e internacional, prestando especial atención a los ámbitos hispanófono y lusófono. Trataremos de examinar en detalle la génesis del original checo y de su traducción alemana. En nuestra investigación hemos recurrido a los métodos de investigación cualitativa empírica del análisis comparado de traducciones y las entrevistas semiestructuradas y, para recabar nuestros materiales de estudio, a la investigación de archivos.

\section{EL ORIGINAL DE EL ARTE DE LA TRADUCCIÓN}

El camino hacia la primera edición de El arte de la traducción (1963) se había iniciado ya en los años cincuenta. En realidad, la publicación de esta monografía puede ser considerada como la culminación de toda una serie de prolongados esfuerzos e investigaciones interdisciplinarias llevados a cabo por el autor².

El primer artículo en el que Levý expone las bases de lo que posteriormente será su doctrina teórica puede ser considerado "Sobre algunas regularidades de la fidelidad traductiva» ("O některých zákonitostech překladatelské věrnosti»), publicado en 1953 en la revista Slovo a Slovesnost (Levý, 1953, pp. 63-80). En esta misma revista apareció en el año 1955 el artículo «El proceso de traducción: sus condiciones objetivas y su psicología» («Překladatelský proces - jeho objektivní podmínky a psychologie») (Levý, 1963, pp. 65-87). Este artículo contiene las bases del manual que el autor y Bohuslav llek publicarían en el año 1956 con el título de Capítulos de la teoría y la metodología de la traducción (Kapitoly z teorie a metodiky prekladu).

En el año 1958 Levý publicó otro manual, Introducción a la teoría de la traducción (Úvod do teorie překladu), en esta ocasión siguiendo muy de cerca la estructura de un artículo publicado previamente en 1957 en la revista Česká literatura con el título "Cuestiones artísticas de la traducción»

${ }^{2}$ En particular, El arte de la traducción trasluce la familiaridad del autor con la lingüística estructural y la filosofía estética.

Hikma 20 (1) (2021), 255 - 274 
(«Umělecké otázky překladu»). El propio autor explicó que «en este libro trato de resumir en una doctrina coherente toda una serie de trabajos sobre traducción literaria aparecidos con anterioridad, para que estén disponibles en forma de una antología» (Levý, 1958, p. 3). Esta obra contiene cuatro capítulos y ya presenta profundas semejanzas con la configuración final de El arte de la traducción, en especial con su primera parte ${ }^{3}$. Vladímir Rossels, el traductor al ruso de la obra fundamental de Levý, consideraba que el manual de 1958 constituye una de las dos etapas fundamentales que condujeron a la creación de El arte de la traducción (Rossels en Levý, 1974, pp. 10-11).

Para la edición de 1963, esta variante fue reelaborada y completada con un resumen actualizado de la bibliografía referida a esta problemática, un nuevo estudio sobre la importancia de los géneros en la literatura traducida, un capítulo dedicado a cuestiones métricas y toda una serie de nuevos ejemplos concretos sobre problemas traductológicos. Los capítulos ya escritos fueron significativamente ampliados, de manera que las 110 páginas del original mecanografiado se convirtieron en una obra de 14 pliegos. Además Levý modificó la estructura y le confirió su organización jerárquica definitiva. Con todo, Rossels consideraba el original de 1963 más bien como un paso intermedio hacia la versión internacional de El arte de la traducción (Rossels en Levý, 1974, p. 13). Sobre esta cuestión trataremos más adelante en el epígrafe «La mediación de El arte de la traducción para los lectores alemanes y rusos».

Finalmente, dentro de este apartado es necesario mencionar dos de los trabajos teóricos más importantes de Levý, su tesis doctoral La evolución de los métodos de traducción en la literatura checa (Vývoj překladatelských metod $v$ české literature) (1957) y su tesis de habilitación Cuestiones fundamentales de la teoría de la traducción (Základní otázky teorie překladu) (1958), que proveyeron materiales indispensables para la configuración final de la obra mayor de Levý. Asimismo, en esta última quedaron reflejados los resultados alcanzados por el autor en toda una serie de trabajos dedicados a cuestiones de estilística y comparatismo literario, como por ejemplo los que consagró a la obra de autores como Karel Čapek, Walt Whitmann y William Shakespeare (Levý, 1955, pp. 513-515; Levý, 1956).

${ }^{3}$ El libro está dividido en dos partes, la primera dedicada a cuestiones generales de teoría y práctica de la traducción, la segunda a la traducción de poesía.

Hikma 20 (1) (2021), 255 - 274 


\section{LA MEDIACIÓN DE EL ARTE DE LA TRADUCCIÓN PARA LOS LECTORES ALEMANES Y RUSOS}

La primera edición de El arte de la traducción despertó muy pronto el interés de los especialistas extranjeros, en primer lugar en Alemania Occidental y Rusia. La editorial Athenäum de Fráncfort encargó una traducción de la obra a Walter Schamschula, que fue considerado como el candidato ideal debido a su origen bilingüe checo-alemán y a sus estudios de eslavística. Según Schamschula, el proceso de traducción se inició en 1965. Simultáneamente, Vladímir Rossels había comenzado la traducción de la obra al ruso, que no vería la luz hasta el año 1974 en la editorial moscovita Progress ${ }^{4}$.

En el prólogo de la edición rusa Rossels explica que el original de $E l$ arte de la traducción presentaba problemas para los traductores por estar enfocado al análisis del ámbito literario y traductológico checo. Por este motivo los traductores se dirigieron a Levý para pedirle que modificase los ejemplos utilizados para aproximarlos a los lectores de las culturas de destino y así facilitar su comprensión (Rossels en Levý, 1974, p. 13). Schamschula coincide con esta apreciación en su prólogo a la edición alemana y añade que Levý se involucró muy activamente en el proceso de adaptación del texto. Debido al carácter innovador de las ideas expresadas por Levý en su libro, en muchas ocasiones era difícil encontrar términos equivalentes en lengua alemana, de modo que Schamschula consultó repetidamente con el autor sobre determinadas formulaciones. Schamschula además nos ofrece un testimonio adicional de que en el mismo momento Levý trabajaba paralelamente en la versión rusa (Schamschula en Levý, 1969, p. 11). A este respecto, Rossels señala que llegó a plantearse la preparación de una versión internacional de El arte de la traducción: «Por aquel entonces Levý comenzó a meditar la preparación de una tercera versión de la obra, una versión de carácter internacional. Al principio pensaba que bastaría con cambiar los ejemplos, pero más tarde se dio cuenta de que cada uno de los cambios exigiría reconstrucciones más amplias y consecuentemente una especificación de las conclusiones» (Rossels en Levý, 1974, p. 13) ${ }^{5}$.

\footnotetext{
${ }^{4}$ Schamschula explica que en su encuentro en Brno en el año 1966 Levý le regaló un ejemplar dedicado de su obra Ciencia literaria y estética occidentales (Západní literární věda a estetika) (Comunicación por correo electrónico del 7 de julio de 2020). Rossels menciona en el prólogo de la traducción rusa que habló por primera vez con Levý en 1965, y al año siguiente tradujo y publicó algunos capítulos de la obra en la antología Cuadernos del traductor (Tetradi perevodchika) (Rossels 1974, 13).

${ }^{5}$ Las traducciones del ruso y el alemán que aparecen en este artículo, a no ser que se indique lo contrario, son mías (J. G.).
} 
A tenor de lo dicho, parece posible preguntarse si nos las tenemos que ver con dos versiones diferentes (a veces se mencionan manuscritos preparatorios completos) para las ediciones alemana y rusa, o si más bien se trata de una reelaboración más general dirigida hacia una versión internacional de la obra. Según Schamschula, no existió ningún manuscrito preparatorio completo de El arte de la traducción que sirviese como patrón para la versión alemana. Más bien el trabajo adaptativo progresaba sobre determinados pasajes que era necesario adaptar para la audiencia alemana, y como patrón general sirvió la versión original de $1963^{6}$.

En el archivo de la Universidad Masaryk de Brno constan documentos que confirman la mencionada cooperación entre Levý y Schamschula, pero que a la vez no permiten descartar la intención del primero de crear una versión internacional de la obra. Se trata de un collage que el autor elaboraba utilizando recortes de la primera edición checa con algunas partes tachadas, posiblemente por considerarlas poco relevantes para el público internacional, e iba añadiendo posibles ideas que pudieran sustituir las partes excluidas. A veces solo reelaboraba determinados segmentos de la primera edición. Como ejemplo podemos mencionar la página $62^{7}$, en el pasaje en que el autor analiza el problema de la «ambigüedad» de las relaciones que se establecen a través de las obras traducidas entre las culturas literarias de partida y meta. En esta adaptación Levý sugiere eliminar el párrafo en el que se describe la situación durante el Resurgimiento Nacional Checo, por considerarlo un contexto excesivamente local, y en su lugar sustituirlo por una reflexión sobre las interpretaciones dispares de François Villon durante el periodo que media entre las dos guerras mundiales. Este párrafo se incorporó después a la versión alemana. En cambio, otro párrafo distinto que también aparece tachado en el documento, y que se refiere a que la literatura traducida puede o bien impulsar el conocimiento de la literatura original o bien competir con ella (como en el caso de la literatura del Resurgimiento Nacional), finalmente sí que apareció en la versión final alemana, con la excepción de unos pocos ejemplos checos (véase Apéndice ํㅜㄴ) ${ }^{8}$.

La mayoría de los materiales preparatorios se encuentran en una carpeta que lleva por título «Descartes de la versión alemana (junto a la adaptación rusa)» (“Zbytky z německé verze (při ruské úpravě)»). En estas páginas se incluyen tanto ejemplos sacados de la literatura alemana como otros tomados de la literatura rusa. Como ejemplo de este modo de trabajo

\footnotetext{
${ }^{6}$ Entrevista con Walter Schamschula, Skype: Praga-Huntsville, 17 de junio de 2020.

${ }^{7}$ La paginación de los documentos en los archivos coincide con la de la versión impresa de El arte de la traducción de 1963.

${ }^{8}$ Archivo de la Universidad Masaryk, Fondo personal de Jiří Levý, B 34 - Notas a la teoría de la traducción, Carpeta 2.
} 
con los materiales podemos citar la página 137 de la carpeta, en la que se trata de la ambigüedad del carácter lingüístico de los personajes dramáticos. Este punto viene ejemplificado con un pasaje de la comedia La bancarrota, de Aleksandr Ostrovski, que se mantiene tanto en la edición alemana, con traducción correspondiente al alemán (Levý, 1969, p. 149) como en la versión rusa, en la que el texto original se contrapone a su traducción checa (Levý, 1974, pp. 204-205). Schamschula considera que la conservación de los ejemplos de la literatura rusa es una confirmación de que Levý trabajaba simultáneamente en las versiones rusa y alemana de su texto, y ello nos daría pie a sospechar que intentaba concertar una compilación destinada a un público lector internacional ${ }^{9}$. En apoyo de esta tesis se podría mencionar que tanto la versión alemana como la edición rusa presentan la misma distribución gráfica de la página. En la misma sección mencionada del capítulo «La traducción de las obras teatrales» («Překlad divadelních her», en ruso «Перевод пьес»), tanto en la versión alemana como en la rusa se utiliza la misma disposición gráfica para mostrar el trabajo con la sintaxis compleja a la hora de traducir el Hamlet (Levý, 1969, p. 128; Levý, 1974, p. 180).

\section{RASGOS ESPECíficos dE LA TRADUCCIÓN ALEMANA DE EL aRTE DE LA TRADUCCIÓN}

Este apartado se enfoca en el análisis detallado de los rasgos específicos de la traducción alemana de El arte de la traducción. Podemos dividirlos en dos grupos fundamentales: rasgos específicos del contenido y rasgos contextuales. Los rasgos específicos del contenido se relacionan con el anclaje de la obra original en el ámbito checo, con lo que se generaban problemas de tipo léxico y pragmático que era necesario confrontar. Los rasgos contextuales, por su parte, se refieren más bien a la situación política de la época y la interrupción repentina de la colaboración entre el traductor y el autor debido a la muerte prematura de este.

Dentro del plano léxico podemos mencionar los problemas que planteaban una serie de conceptos teóricos que debían transferirse por primera vez al alemán, lo que se refleja en un tratamiento ocasionalmente inconsistente de algunos de ellos. Como ejemplo podemos mencionar el concepto de «traductividad» («překladovost») (Levý, 1963, p. 60). Se trata de un neologismo de Levý que posteriormente fue desarrollado por Anton Popovič (1983, p. 177). Levý definía la traductividad desde dos sesgos diferenciados. En primer lugar, traductividad es la cualidad general por la que una obra revela que es una traducción y, en segundo lugar, esta cualidad puede considerarse en épocas distintas como valorada positiva 0 negativamente. Schamschula traduce este concepto al alemán como "das

${ }^{9}$ Comunicación con Walter Schamschula por correo electrónico, 7 de julio de 2020.

Hikma 20 (1) (2021), 255 - 274 
Übersetztsein», lo que quizá se podría retraducir al español con la fórmula «el ser traducción» (Levý, 1969, p. 74), aunque en otras oportunidades emplea el sustantivo adjetival "das Übersetzerische», o sea «lo traductivo» (Levý, 1960 , p. 176). En ambos casos utiliza el término en un sentido valorativo.

De acuerdo con los materiales de archivo de que disponemos, Levý recibió un último manuscrito de la traducción alemana para efectuar correcciones. Llegó a revisar una parte de este manuscrito antes de su repentina muerte, pero Schamschula explica que estas correcciones nunca le llegaron ${ }^{10}$. El manuscrito con estas correcciones, que se conserva en el fondo personal de Jiří Levý, contiene sobre todo enmiendas de tipo léxico, diacrítico y de disposición gráfica, aunque en algunas ocasiones encontramos correcciones más relevantes como adiciones u omisiones. Sin embargo, a la vez cabe constatar que algunas partes de la traducción final se diferencian tanto del manuscrito original como de la corrección sugerida por Levý ${ }^{11}$. Un ejempo de ello es la traducción de la siguiente frase: «El texto de la obra se realiza socialmente y afecta de manera artística únicamente en el caso de ser leído» («Text díla se společensky realizuje a umělecky působí teprve tehdy, je-li čten») (Levý, 1963, p. 20). En el manuscrito de la traducción alemana originalmente aparecía la siguiente formulación: « Der Text eines Werks wird in der Gesellschaft der Leser realisiert und wirkt als Kunstwerk erst dann, wenn er gelesen wird». En la corrección a este pasaje Levý recomienda cambiar «Gesallschaft der leser» (traducción literal: «la comunidad de los lectores») por la expresión «Leserpublikum» (traducción literal: «el público lector» ${ }^{12}$. Sin embargo, en la versión final encontramos la variante: «Kulturmilieu des Lesers» (traducción literal: «ámbito cultural del lector») (Levý,1969, p. 37).

Las adaptaciones de contenido más notables desde el punto de vista de la pragmática fueron aquellas que venían exigidas por el carácter particular de los ejemplos que Levý utilizaba para ilustrar una determinada tesis teórica. En sus correcciones, vemos que Levý realizó un importante esfuerzo por encontrar paralelismos adecuados en la literatura alemana de los ejemplos checos que servían para demostrar sus conceptos traductológicos. En el original checo, en el capítulo «La interpretación del patrón» («Interpretace předlohy»), Levý recurre a la traducción de Saudek de La fierecilla domada para demostrar la intervención de la subjetividad del traductor en su traducción: Saudek había cambiado todos los topónimos de las cercanías de

\footnotetext{
${ }^{10}$ Comunicación con Walter Schamschula por correo electrónico, 7 de julio de 2020.

${ }^{11}$ Cabe preguntarse si ello se debe a que no se trataba de la última corrección antes de imprenta o porque la corrección no llegó al editor o al traductor.

${ }^{12}$ Archivo de la Universidad Masaryk, Fondo personal de Jiř́ Levý, B 34 - Notas a la teoría de la traducción,, Carpeta 1.
} 
Stratford por los de su propia región natal (Levý, 1963, p. 32). Dentro del ámbito alemán, encontró una tendencia parecida en la traducción de Heinrich Zschokke de la obra de Molière Précieuses ridicules. En los archivos de la Universidad Masaryk se encuentra una versión mecanografiada de esta traducción en la que Levý había destacado y anotado detalladamente algunos pasajes que, en su opinión, podían ilustrar el subjetivismo de Zschokke, y que se corresponden muy directamente con las intervenciones señaladas de Saudek en el original checo. Sin embargo, en el texto final de la versión alemana solo encontramos una mención general a Zschokke como traductor que dejaba traslucir sus simpatías y antipatías literarias en sus traslaciones (Levý, 1969, pp. 48-49). Una vez más, cabe preguntarse si esta nota llegó o no a manos del editor o del traductor antes de la publicación de la versión alemana $^{13}$.

Aparte de los rasgos específicos del contenido, los rasgos específicos contextuales tuvieron una gran importancia durante todo el proceso de traducción de la obra. De acuerdo con los datos que figuran al final de una de las páginas del manuscrito alemán el texto estaba ya completo en el año 1967, pero no llegó a publicarse. En la introducción que escribió en el año 1968 Schamschula señala que el prólogo a la versión alemana fue el último trabajo que Levý logró completar en vida. Sin embargo aquí se puede precisar que este prólogo es una reelaboración del capítulo introductorio que aparecía ya en el original checo: «El estado del pensamiento teórico sobre la cuestión de la traducción» (en alemán: «Der Stand der theoretischen Beschäftigung mit den Fragen des Übersetzens»). Levý lo actualizó para la versión alemana teniendo en cuenta los últimos desarrollos en teoría de la literatura y lingüística en el ámbito internacional (Levý, 1969, p. 11)

La muerte de Levý a principios de 1967 tuvo consecuencias tanto para la publicación de la versión alemana como de la rusa. Levý enviaba a Rossels de manera regular capítulos individuales de la obra orientados al público lector ruso. El último de ellos llegó a Moscú ya después de la muerte del autor (Rossels en Levý, 1974, p. 16). Por su parte, Schamschula señala que después del inesperado fallecimiento le quedaban muchas dudas y puntos oscuros que hubiese querido consultar detenidamente con el autor. Tuvo que terminar la traducción esforzándose todo lo posible por conservar la armonía entre las ideas y el estilo expresivo del autor. Además actualizó la bibliografía internacional de teoría y práctica traductológica a partir de las anotaciones dejadas por Levý y de la correspondencia que habían mantenido mientras colaboraban.

${ }^{13}$ Archivo de la Universidad Masaryk, Fondo personal de Jiří Levý, B 34 - Notas a la teoría de la traducción, Carpeta 4. 
Finalmente, no cabe duda de que la situación política de la época influyó de manera notable en el aspecto final de la traducción alemana y en las posibilidades de trabajo conjunto entre el autor y el traductor de la obra. Schamschula tiene la convicción de que la correspondencia con Levý fue vigilada por los aparatos de censura y de que parte de los materiales enviados nunca llegaron a Fráncfort ${ }^{14}$.

\section{EDICIONES POSTERIORES CHECAS DE EL ARTE DE LA TRADUCCIÓN}

La segunda edición checa de El arte de la traducción fue publicada en 1983 por Karel Hausenblas, lingüista de formación pero con amplios intereses intelectuales y que durante su carrera se había dedicado en repetidas ocasiones a cuestiones de teoría de la traducción. Entre otras cosas, fue autor del artículo «Estilo y traducción» (1967/68, pp. 13-36), de una reseña con motivo de la aparición de la primera edición del volumen de Levý y de una serie de escritos de temática traductológica que se conservan en el fondo personal del autor en la Universidad Karl Marx de Leipzig ${ }^{15}$.

En su reseña a la primera edición de El arte de la traducción, «Traducción y teoría de la literatura. Sobre el libro de J. Levý El arte de la traducción» («Překládání a teorie literatury. Nad knihou J. Levého Umění překladu»), publicada en el año 1965, Hausenblas había reprochado a Levý, entre otras cuestiones, una fundamentación poco rigurosa del concepto de «traducción realista» («realistický překlad»): «Este concepto no está definido de manera explícita y confieso que no acabo de entender qué es lo que debemos representarnos bajo este término». En su opinión, se plantean dos tipos de problemas, por un lado la indefinición creada por la ausencia de una definición de la traducción de tipo «no realista», y por otro la falta de clarificación histórica sobre el ámbito de aplicación del concepto. Es decir, si el realismo se entiende aquí en su acepción amplia de "el arte sano, progresivo, presente en todas las épocas», o bien en su acepción más estrecha de «una tendencia artística determinada que cobró auge en nuestra literatura en las últimas décadas del siglo XIX» (1965, pp. 161-162).

Levý tomó en consideración esta crítica e introdujo una modificación en la versión alemana, en el capítulo introductorio «Die literaturwissenschaftlichen Methoden» (Levý, 1969, pp. 27-28), que después pasaría a la segunda edición checa con el título "Métodos de la teoría literaria» («Literárněvědné metody»): «El concepto de "realismo" puede ser

${ }^{14}$ Conversación personal con Walter Schamschula, Skype: Praga-Huntsville, 17 de junio de 2020.

${ }^{15}$ Sobre la aportación personal de Hausenblas a los estudios de traducción se han manifestado positivamente autores como Gert Jäger, en Zur Problematik von Gegenstand und Objekt , u Otto Kade, en Kommunikationswissenschaftliche Probleme der Translation. 
entendido en un sentido histórico literario (como un determinado método elaborado por los realistas críticos de los siglos XVIII y XIX) o en sentido filosófico (la actitud gnoseológica correspondiente al materialismo dialéctico» (Levý, 1983, pp. 34-35). Añade que determinados autores soviéticos emplean el término de "realismo» como sinónimo de «adecuado», pero que en el contexto de su reflexión traductológica esta aprehensión pierde parte de su sentido concreto (Levý, 1983, pp. 34-35). La primera edición de su obra también incluía un capítulo individual con el título «El realismo en la traducción» («Realismus v překládání») (Levý 1963, 49) que fue alterado y aparece en la versión alemana y en la segunda edición checa como «Los problemas estéticos de la traducción» («Estetické problémy v překladu») (Levý, 1983, p. 82). Sin embargo, el contenido del capítulo permanece intacto, con lo que el autor da a entender que en la primera edición del texto la noción de «traducción realista» refería un tipo de traducción «adecuada» o "veraz».

En su reseña Hausenblas también criticaba el paralelismo que trazaba Levý entre el arte dramático y la traducción, debido a que el fin primario de una traducción no es el de representarse en la escena. También discutía la diferenciación entre «el texto de la obra y la obra en un sentido más reducido" y la elección de las palabras como mínima unidad semántica independiente. Levý no dio respuesta a ninguna de estas críticas en ninguna de las reelaboraciones que llevó a cabo. Así pues, si observamos la relación ambivalente de Hausenblas respecto de la obra de Levý, cabe preguntarse acerca de la actitud con la que encaró las tareas de preparación de la segunda edición del libro. El propio Hausenblas se pronunció de la siguiente manera en su prólogo:
Nuestra intención era la de aprovechar en todo lo posible la versión alemana en la nueva edición del libro. Sin embargo, más tarde se demostró que esto no era tan sencillo. No era posible partir de esta versión como aquella que correspondía a la «última intención» del autor por el hecho de que estaba destinada a otros lectores, a lectores de otro ámbito lingüístico, literario y cultural. Tampoco resultaba conveniente optar por ampliar la primera versión con todas las adiciones efectuadas a la edición alemana, puesto que además de añadir contenidos también se habían introducido numerosas modificaciones (Hausenblas en Levý, 1983, p. 10, traducción propia).

Poco después añade: «No es necesario que estemos de acuerdo en todos los puntos con las argumentaciones de Levý. Ya con motivo de la primera aparición del libro, junto con las numerosas críticas positivas, se señalaron algunas objeciones». También admite que un cierto grado de subjetividad era inevitable a la hora de efectuar la selección y combinación de las dos versiones previas que manejaba. Sin embargo, asegura haber 
puesto especial cuidado en intervenir lo menos posible y señala que solo en muy pocos casos ha modificado la redacción original para que el texto fuera más fluido.

El análisis comparativo nos permite comprobar que Hausenblas procuró recuperar en su edición todas las ideas que figuraban en el texto original y que habían sido descartadas en la traducción alemana. Como ejemplo podemos mencionar la cita de Otokar Fischer «una traducción debe ser libre, en la medida en que lo permita la exigencia de fidelidad» (Levý, 1963 , p. $51 ; 1983$, p. 85), que se restituye a su lugar en la sección dedicada al papel de la creatividad en la búsqueda de equivalentes traductivos en el capítulo "La traducción como género artístico» ( «Překladatelství jako typ umění»). A la vez, es indudable que intentó también incorporar todas las adiciones alemanas en su nueva edición. Hausenblas menciona en el prólogo que tenía conocimiento de la existencia de una última corrección anotada por Levý, pero explica que no la tuvo a su disposición para trabajar con ella (Hausenblas en Levý, 1983, p. 11). En el capítulo «El proceso de traducción» («Překladatelský proces»), además de la explicación inicial de las tres fases del trabajo del traductor, el editor incluye la representación de la traducción como una doble cadena de comunicación (Levý 1969, p. 33; 1989, p. 42).

El capítulo que presentaba mayor margen de decisión acerca de qué mantener y qué excluir era «La traducción de las obras teatrales» («Překládání divadelních her», en alemán «Die Übersetzung von Theaterstücken»). Este capítulo había sido sometido a sustanciales modificaciones desde la primera edición. En 1968 apareció como artículo exento, en alemán, en la revista $B a b e l$, con cambios en la estructura, nuevos epígrafes y toda una serie de nuevos ejemplos internacionales, no siempre tomados del ámbito específico teatral o alemán. Hausenblas no siempre conservó estas adiciones. En el capítulo «Oralidad e inteligibilidad» («Mluvnost a srozumitelnost», en alemán «Die Sprechbarkeit und die Verständlichkeit»), Levý describe una de las posibilidades de cómo medir la comprensibilidad y dificultad del discurso teatral mediante un cloze test psicolingüístico en el que el participante debe adivinar las palabras ausentes en un texto. En la edición alemana aparecían los resultados de este estudio estadístico llevado a cabo por Levý sobre un grupo de traducciones checas de obras de teatro. También en esta ocasión el editor sigue la redacción de la edición de 1963 y no mantiene el análisis estadístico (Levý, 1983, p. 164).

La editorial Panorama nominó a Karel Hausenblas por su trabajo al premio del Fondo Literario Checo. El director de la editorial, František Hanzlík, destaca en su informe la contribución de la obra y los obstáculos que el editor tuvo que superar durante la preparación de la segunda edición. Ensalza sobre 
todo la manera en que Hausenblas consiguió enlazar y conectar el texto original con la traducción sin que se notasen los cortes ${ }^{16}$.

Después de la segunda edición de 1983 siguieron otras dos publicaciones de El arte de la traducción. En 1998 la obra fue publicada por la editorial Ivo Železný. Según la nota del editor se trata de una reimpresión de la segunda edición con mínimas intervenciones editoriales (Železný en Levý 1998, 391). La cuarta y última edición de la obra fue publicada en 2012 por la editorial Apostrof y fue preparada por Miroslav Pošta. Además de las ediciones segunda y tercera, también tuvo en cuenta la traducción inglesa del libro aparecida en el año 2011. Aparte de la omisión de algunas referencias a la filosofía marxista, debida a los cambios en la situación política, lo más destacable de esta edición es la revisión de algunas partes problemáticas y sobre todo la corrección de errores en ejemplos en lenguas extranjeras que se habían deslizado de una edición a otra ${ }^{17}$.

\section{LA RECEPCIÓN DE EL ARTE DE LA TRADUCCIÓN EN EL EXTRANJERO}

La primera versión extranjera de El arte de la traducción, Die literarische Übersetzung: Theorie einer Kunstgattung (1969) se convirtió en la fuente fundamental no solo para la segunda edición checa (1983), sino sobre todo para la difusión de las ideas de Levý entre el público especializado internacional. Según José Lambert, la versión alemana de la obra había transformado la visión que se tenía en Occidente acerca de la literatura traducida (Jettmarová en Levý, 2012, pp. 8-9).

Las ideas de Levý influyeron sobre todo en la teoría de los polisistemas y la escuela de la manipulación. En los años setenta, un grupo de teóricos literarios agrupados en torno a la figura de James Holmes se inspiró en Levý. Holmes conocía de primera mano las últimas innovaciones internacionales en el ámbito de la teoría de la traducción y sus competencias lingüísticas le permitían leerlas en su lengua original. En su obra encontramos constantes corroboraciones de que conocía bien las tesis de Levý. Las nociones de «norma reproductiva» y «norma artística» de Levý tienen estrechos paralelismos con las dos reglas fundamentales que distinguió Holmes para la traducción poética: por un lado la exigencia de fidelidad, de modo que la traducción no sea considerada una obra completamente independiente, y por otro la exigencia de poeticidad, de modo que el producto final pueda seguir considerándose como un poema (Šmrha, 2015, pp. 23-24).

\footnotetext{
${ }^{16}$ Archivo Estatal Regional, Fondo de la editorial Panorama, $n^{0}$ 6, carpeta 6: Litfond 1979-1984. Sin embargo, no queda claro si finalmente Karel Hausenblas llegó a recibir el premio.

${ }^{17}$ Comunicación con Miroslav Pošta por correo electrónico, 31 de julio de 2020.
} 
El principal representante de la teoría de los polisistemas, Gideon Toury, al cual se le suele atribuir en la traductología occidental la introducción del concepto de «norma» en los estudios de traducción, explicó en una entrevista concedida en Toronto en el año 2003 que había trabado conocimiento con esta noción de norma traductiva por primera vez en el año 1974, al leer la disertación de su maestro Itamar Even-Zohar, en la que se explicaban detalladamente las tesis de Levý (Jettmarová, 2016, pp. 106). André Lefevere, el fundador de la escuela de la manipulación, que surgió como una determinada escisión de la teoría de los polisistemas en la década de los ochenta, también partió en su trabajo de los conceptos elaborados por Levý. Según Lefevere, el traductor debe poseer un conocimiento profundo de la propia tradición literaria, que le permita «rellenar» los huecos existentes en su desarrollo (Šmrha, 2015, p. 40). Esta noción recuerda muy de cerca la exposición de Levý en el capítulo «La relación ambigua con la literatura de partida» («Dvojznačný vztah k původní literatuře»).

La influencia de Levý la podemos encontrar también en otras corrientes teóricas y autores del ámbito de los estudios de la traducción. Ya antes habían encontrado inspiración en él tanto la escuela de los Países Bajos (the LowCountries School) como la escuela de Nitra (Jettmarová, 2016, p. 9). El fundador de la escuela traductológica de Leipzig, Otto Kade, también hace referencias a El arte de la traducción, y además no a la versión alemana sino a la original checa de 1963. Kade llega a considerar este libro como la contribución más importante para delinear una teoría completa de la traducción literaria (Benešová, 2019, p. 19).

La teoría traductológica de Levý coincidió cronológicamente con las tesis de autores como George Mounin, John Catford o Eugene Nida durante la década de los años sesenta (Jettmarová, 2016, p. 9). Durante mucho tiempo la obra de Levý quedó marginada por diversos motivos de peso. El primero de ellos es la situación política que limitaba la circulación de ideas y la discusión académica entre los países del Bloque del Este y sus interlocutores occidentales. El segundo es el carácter minoritario de la lengua checa en la que fueron expresadas estas ideas, a la que pocos estudiosos tenían acceso directo. Finalmente, otro motivo importante fue la conceptuación distorsionada de la aportación de Levý y su clasificación errónea dentro de las descripciones de la evolución histórico-teórica de la disciplina. Levý fue encasillado como un representante del paradigma lingüístico en los estudios de traducción cuando en realidad sus concepciones teóricas y metodológicas se adelantaban a las premisas habituales en su época. El arte de la traducción partía de las tesis elaboradas por el estructuralismo funcional checo, un movimiento teórico cuya aportación solía interpretarse de manera distorsionada como un mero sucesor del formalismo 
ruso o un precedente ofuscado de la teoría de los polisistemas. Dentro de esta interpretación señalada, la obra de Levý quedaba situada implícitamente como algo del pasado, ya superado, y se exageraban sus vínculos con las tesis del estructuralismo francés. Esta interpretación desafortunada afectaba no solo a Levý sino de manera general al conjunto del estructuralismo checo.

Existen determinadas propuestas teóricas de Levý que en efecto se encontraban en consonancia con los presupuestos epistemológicos dominantes en su momento. Esto se refiere sobre todo a las ideas contenidas en el artículo «La traducción como proceso de toma de decisiones» («Překlad jako rozhodovací proces»), que no por casualidad fue traducido tempranamente al inglés con el título "Translation as a Decision Process» y tuvo bastante popularidad (Schultze, 2015, p. 109). Sin embargo, como explica la profesora $Z$. Jettmarová, en este artículo no aparecían nociones fundamentales de Levý como las de "norma», "función» o "equivalencia» (2016, pp. 95-99). En uno de los manuales de consulta más recurrentes en los estudios de traducción, la International Encyclopaedia of Translation Studies, el nombre de Levý aparece mencionado 45 veces, pero casi todas ellas se refieren precisamente a este artículo mencionado.

Hoy por hoy, se puede decir que El arte de la traducción suscita un interés creciente en el ámbito internacional. Esto se debe en parte a la traducción inglesa de la obra que salió finalmente a la luz en el año 2011, gracias a la colaboración entre Patrick Corness y Zuzana Jettmarová. El traductor y la redactora partieron en su trabajo de la segunda edición de Karel Hausenblas y de la versión alemana, aunque también tuvieron en cuenta la traducción rusa en algunas partes. En 2018 esta traducción inglesa fue vertida al chino y publicada por la editorial China Intercontinental Press, con un prólogo escrito por Cong Li. En el continente africano la versión inglesa de la obra sirve como manual de estudio para los estudiantes de los seminarios de traducción en la Universidad de Dar es Salaam, en Tanzania, y la Universidad de Namibia ${ }^{18}$.

\section{EL ARTE DE LA TRADUCCIÓN EN ESPAÑA}

Las ideas y conceptos teóricos de Jiří Levý fueron introducidos en España por primera vez gracias al traductor e historiador de las ideas traductológicas Miguel Ángel Vega, que incluyó uno de los capítulos de su obra en su volumen Textos clásicos de la teoría de la traducción (1994), en concreto el que lleva el título de "Las dos normas de la traducción artística» («Podvojnost přeloženého díla»). Vega utilizó la versión alemana de

${ }^{18}$ La autora de estas páginas tuvo la oportunidad de convencerse de ello durante las estancias de investigación realizadas en los años 2018 y 2019 en ambos países, bajo la dirección de los profesores Kristomus Faraja, en Tanzania, y Marianne Zappen-Thompson, en Namibia. 
Schamschula para efectuar la traducción española. En 2011 el autor también publicó un estudio dedicado a la obra de Levý: «El caso Levý: Fenomenología de su recepción y valoración de sus aportaciones en el contexto de la traductología de la época». Vale la pena destacar que ambos estudiosos coinciden en buena parte de sus conceptuaciones acerca de la traducción: ambos investigan el proceso traductivo como proceso de tomas de decisiones, están interesados en el papel fundamental que juega el traductor dentro de los procesos de comunicación cultural y destacan el aspecto creativo de la traducción tanto en relación con el texto original como con el receptor en la cultura de llegada. Ambos también enfatizan la importancia del uso práctico de la teoría de la traducción e investigan la historia de las concepciones traductológicas (Marksová, 2014, pp. 16-17).

A partir del año 2010 se produce un cierto auge en las aportaciones españolas que parten de los postulados de Levý. Juan Miguel Zarandona, en su reseña del libro Tradition versus Modernity. From the Classic Period of the Prague School to Translation Studies at the Beginning of the 21st Century, destaca que todas las contribuciones en este volumen colectivo tienen un denominador común: el legado del fundador de la traductología checa, Jiří Levý, y la puesta en valor de un acercamiento de tipo funcional a los hechos traductivos. Juan Antonio Albaladejo, por su parte, utiliza las ideas de Levý en su ensayo de 2011 «El préstamo entre transparencia y opacidad: ¿Medio o impedimento en la comunicación intercultural?». En concreto trabaja con la noción de la doble naturaleza de la traducción y adopta la tesis de que el traductor suele tener la intención de mejorar el original y que el crítico de la traducción debe ser muy precavido en sus evaluaciones.

El siguiente hito en la recepción de Levý en el ámbito peninsular español llegó de la mano de la publicación de la antología Jiři Levý: una concepción (re)descubierta, a cargo de Jana Králová y Miguel Cuenca Drouard, en la que se presentaba una selección de los textos clave del autor. Ya en 2011, en su artículo «Překladovost y posun: ¿Causa o consecuencia?», Cuenca Drouhard había investigado las posibles traducciones del neologismo mencionado anteriormente de "překladovost». En su volumen conjunto, Králová y Cuenca Drouhard incluyeron el prólogo y el epílogo de la obra Teorías checas de la traducción (České teorie prekladu) (1957), capítulos escogidos de El arte de la traducción (Umění překladu) (1963), otros de la obra póstuma ¿Será la teoría literaria una ciencia exacta? (Bude literární věda exaktní vědou?) (1971) y versiones reducidas de los ensayos "Génesis y recepción de la obra literaria» ("Geneze a recepce literárního díla»), "Las traducciones de Karel Čapek en la evolución del arte de traducir y del verso checo» («Čapkovy překlady ve vývoji českého překladatelství a českého verše») y «¿Será la teoría de la traducción útil para los traductores?» («Bude 
teorie překladu užitečná překladatelưm?») (Mračková Vavroušová, 2018, pp. 144-147).

\section{EL ARTE DE LA TRADUCCIÓN EN AMÉRICA LATINA}

Las teorías de Levý fueron introducidas en América latina en 2011 gracias a la disertación de Filipe Mendes Neckel Die literarische Übersetzung [dissertação]: apresentação da obra de Jiř́ Levý acompanhada de uma tradução comentada. Se trata de una traducción comentada de uno de los capítulos de El arte de la traducción, «Las tres fases del trabajo del traductor», que precedió a la publicación de la traducción completa del libro en una versión paralela alemana-portuguesa. Neckel toma como punto de partida exclusivo la versión alemana de Schamschula, a la que concede el estatuto de original. A diferencia de Levý, no adaptó la traducción al ámbito cultural y literario portugués y no sustituyó los ejemplos dados en el libro por sus analogías portuguesas. Es decir, la versión de Neckel es una copia fiel de su patrón alemán (Mračková Vavroušová, 2019, pp. 30-31).

En 2012 la revista Scientia Traductionis, publicada por la Universidad Federal de Santa Catarina, dedicó al autor checo su número temático «(Re)descobrindo Jiří Levý», en el que por primera vez se ponía a disposición del público en lengua portuguesa un buen número de sus ensayos más importantes con traducciones paralelas al inglés, el alemán o el español. En el año 2016 la revista Mutatis Mutandis publicó un número especial con el título "The Art of translation: Jirí Levý (1926-1967) y la otra historia de la Traductología», resultado de la colaboración entre la Universidad de Antioquía, la Universidad de Santa Caterina y la Universidad Carolina de Praga (Mračková Vavroušová, 2018, pp. 149-150). Si bien la estructura y el espacio disponible no permitieron dar una visión exhaustiva de todo el conjunto de la obra de Levý, los acertados criterios de selección de los editores permitieron aproximar las conceptuaciones de Levý a las discusiones y problemas más candentes de la disciplina de la traductología de hoy en día (Brabec, 2018, p. 172).

La obra de Levý recibe una atención especial en el libro de Sergio Bolaños Introducción a la traductología: Autores, textos y comentarios (2016), que podría considerarse como el primer intento de elaborar un resumen completo de la historia de la traductología en América Latina. Bolaños, profesor de la Universidad Nacional de Colombia en Bogotá, sitúa a Levý en la sección dedicada a los precursores de la teoría contemporánea de la traducción, discute detalladamente sus ideas y las pone en relación con las de otros autores y otras corrientes. Menciona todos los capítulos de la obra mayor del autor checo con la excepción de «La traducción de las obras de teatro» y «La traducción como problema histórico-literario». Cabe mencionar 
que Bolaños trabaja con las ideas de Levý a partir de la traducción rusa de 1974 (Venegas Piracón, 2017, p. 264).

\section{CONCLUSIONES}

En nuestro trabajo nos habíamos propuesto dos objetivos fundamentales. El primero de ellos era el de describir la gestación del original de El arte de la traducción como un proceso de reescrituras que se remonta a mucho antes de la primera edición del libro en 1963, y se prolonga durante mucho tiempo después, en especial a través de las traducciones alemana y rusa, quedando interrumpido a consecuencia del desdichado fallecimiento del autor. Dentro de este proceso la definición o determinación estricta de un manuscrito original pierde parte de su pertinencia, pero ello no obsta para que los editores y también los lectores sucesivos se relacionen de manera rigurosa y leal con los materiales disponibles, como en efecto lo han hecho una serie de estudiosos que han tratado de dar a conocer el pensamiento teórico del autor. El segundo de nuestros objetivos, que en parte se entrelazaba con el primero, era el de describir los accidentados avatares de la recepción internacional de Levý, con especial referencia a los ámbitos hispanófono y lusófono. En este sentido, estamos de acuerdo con las conclusiones de Petra Mračková Vavroušová de la asimilación de las ideas del autor en España y América Latina «no ha sido tan escasa como quizá se podría esperar» (2018, p. 151). Esperamos que nuestro artículo sea una contribución más dentro de una larga cadena de esfuerzos que, como hemos tenido oportunidad de ver, en la actualidad está comenzando a rendir sus frutos.

En su artículo «Génesis y recepción de la obra literaria» (1971), Levý criticaba lo que consideraba como excesivo «eidocentrismo» de los estudios literarios y traductológicos del momento, es decir, la focalización exclusiva en las relaciones internas inmanentes de los textos, y abogaba por una metodología de análisis que tuviese en cuenta lo que ocurre también «antes de la obra» y «después de la obra»: "el dinamismo de la génesis y el dinamismo de la recepción» $(2013$, p. 120). Se trata de un aspecto en el que Levý excede claramente las premisas metodológicas y epistemológicas del estructuralismo lingüístico dominante en su momento y, a partir de su entronque con la tradición conceptual del estructuralismo funcional de la Escuela de Praga, apunta hacia una serie de discusiones que marcan la actualidad polémica de la disciplina de la traductología. En nuestra opinión, la lectura atenta de las tesis de Levý, una vez superada una interpretación restrictiva y empobrecedora de sus ideas, puede servir como estímulo para la delineación de nuevas perspectivas teóricas y analíticas en el futuro. 


\section{REFERENCIAS BIBLIOGRÁFICAS}

Benešová, Rut. (1999). Otto Kade a jeho př́nos translatologii. Trabajo de máster bajo la dirección de Tomáš Svoboda. Praga: Facultad de Letras de la Universidad Carolina.

Grygar Mojmír. (1999). Terminologický slovník českého strukturalismu: obecné pojmy estetiky a teorie umění. Brno: Host.

Hausenblas, Karel. (1963). «Překládání a teorie literatury (Nad knihou J. Levého Umění Překladu)». Česká literatura 13: 155-168.

Hausenblas, Karel. (1967/1968). «Styl a překlad». Dialog 11 (1): 13-36.

Jettmarová, Zuzana. (2018). «Bibliografie Jiřího Levého». En AUC Philologica - Translatologica Pragensia 2: 185-198.

— (2016). Mozaiky překladu. Praga: Karolinum.

Kitzbichler, Josefine, Katja Lubitz a Nina Mindt. (2009). Theorie der Übersetzung antiker Literatur in Deutschland seit 1800. Berlin: Walter de Gruyter.

Harald, Kitler (ed.). (2011). Übersetzung: An international encyclopedia of translation. Berlin: Walter de Gruyter.

Levý, Jiří. (1953). «Oněkterých zákonitostech překladatelské věrnosti». Slovo a slovesnost 14 (2): 63-80.

— (1955). «Překladatelský proces - jeho objektivní podmínky a psychologie». Slovo a slovesnost, 16 (2): 65-87.

— (1955). «Walt Whitman v českých překladech». Host do domu 11 (2): 513515.

— (1956). «Čapkův Loupežník a Shakespeare». Jazyk a literatura 3. Sborník Vysoké školy pedagogické v Olomouci. Praga: SPN.

—. (1957). «Umělecké otázky překladu», Česká literatura 5 (4): 379-401.

- (1958). Úvod do teorie překladu. Praga: Státní pedagogické nakladatelství.

— (1963). Umění překladu. Praga: Československý spisovatel.

- (1966). Západní literární věda a estetika. Praga: Československý spisovatel.

— (1968). «Die Übersetzung von Theaterstücken». Babel 14 (2): 77-82. 
- (1969). Die literarische Übersetzung: Theorie einer Kunstgattung. Traducción de Walter Schamschula. Frankfurt am Main/Bonn: Athenäum Verlag.

- (1974). Iskusstvo perevoda. Traducción de Vladimir Rossels. Moskva: Progress.

— (1983). Umění překladu. Praga: Panorama.

— (1998). Umění překladu. Praga: Ivo Železný.

- (2011). The Art of Translation. Traducción de Patrick Corness. Amsterdam/Philadelphia: John Benjamins Publishing Company.

— (2012). Umění překladu. Praga: Apostrof.

- y Bohumil llek. (1956). Kapitoly z teorie a metodiky překladu. Praga: Státní pedagogické nakladatelství.

Marksová, Romana. (2015). Miguel Angel Vega a jeho př́nos k rozvoji translatologie. Tesis de máster bajo la dirección de Jana Králová. Praga: Facultad de Letras de la Universidad Carolina.

Mračková Vavroušová, Petra. (2018). «Soudobá recepce díla Jiř́ho Levého ve Španělsku a Iberoamerice». AUC Philologica - Translatologica Pragensia 2: 143-153.

Popovič, Anton. (1983). Originál - preklad: interpretačná terminológia. Bratislava: Tatran.

Schultze, Brigitte. (2015). «Jiří Levý's Contribution to Translation Studies as represented in the De Gruyter Encyclopedia Übersetzung, Translation, Traduction». AUC Philologica - Translatologica Pragensia 3: 105-112.

Šmrha, Jan. (2015). André Lefevere a jeho manipulační škola. Tesis de maestría bajo la dirección de Zuzana Jettmarová. Praga: Facultad de Letras de la Universidad Carolina.

Venegas Piracón, Laura Esperanza. (2017). «Reseña de libro: Introducción a la traductología: Autores, textos y comentarios». Mutatis Mutandis 10 (2): 263-267. 